\title{
Corrosion of Mg-9Al alloy with minor alloying elements (Mn, Nd, Ca, Y and
} $\mathrm{Sn})$ \author{
M.C. Merino ${ }^{\mathrm{a}}$, A. Pardo ${ }^{\mathrm{a}}$ \\ a Departamento de Ciencia de Materiales, Facultad de Ciencias Químicas, Universidad Complutense, 28040 Madrid, Spain \\ b Brunel Centre for Advanced Solidification Technology, Brunel University London, Uxbridge UB8 3PH, United Kingdom \\ ${ }^{c}$ Magnesium Innovation Centre, Helmholtz-Zentrum Geesthacht, 21502 Geesthacht, Germany
}

B. Mingo ${ }^{a}, *, R$. Arrabal $^{a}$, M. Mohedano ${ }^{a}$, C.L. Mendis ${ }^{b, c}$, R. del Olmo ${ }^{a}$, E. Matykina ${ }^{a}$, N. Hort ${ }^{c}$

\section{A R T I C L E I N F O}

\section{Keywords:}

Magnesium

Rare earth

Corrosion

SKPFM

Volta potential

EPMA

\begin{abstract}
A B S T R A C T
Microstructure and corrosion behaviour of a Mg-9Al alloy with minor alloying additions (Mn, Y, Nd, Ca and Sn) are evaluated. All of the additions form Al-rich intermetallics with varying amounts of $\mathrm{Fe}$, while $\mathrm{Ca}$ and $\mathrm{Sn}$ are also incorporated into the eutectic $\beta$-phase $\left(\beta-\mathrm{Mg}_{17} \mathrm{Al}_{12}\right)$. Special attention is given to the surface potential values of the microconstituents, which are related to the formation of microgalvanic couples. Scanning Kelvin Probe Force Microscopy (SKPFM) measurements revealed that all the alloying elements, except Sn, reduced the potential difference between the secondary phases and the matrix, which is the main reason for the improvement of the corrosion resistance of Mn-, Y- and Nd-modified alloys. The beneficial effect of Ca is additionally related to the microstructure refinement and an increased area fraction of the $\beta$-phase.
\end{abstract}

G R A P H I C A L A B S T R A C T

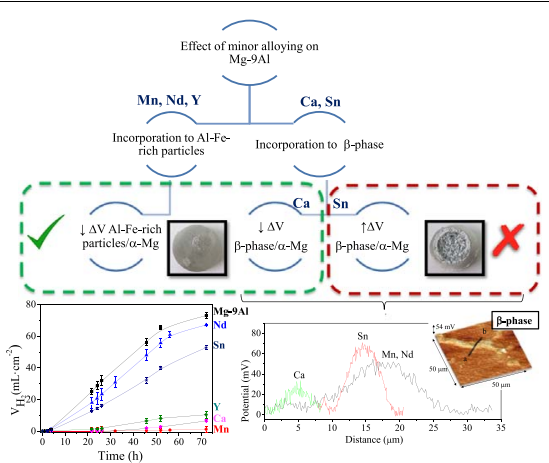

\section{Introduction}

The interest to $\mathrm{Mg}$-based materials is mainly associated with their high specific strength, good castability and damping capacity [1]. However, the outstanding potential of $\mathrm{Mg}$ alloys for weight-sensitive applications, such as in automotive components [2,3], can only be realised under mild service conditions due to poor creep resistance of the alloys at high temperatures $\left(>120^{\circ} \mathrm{C}\right.$ ) and poor corrosion behaviour $[4,5]$.

$\mathrm{Al}$ is the most common alloying element in cast $\mathrm{Mg}$ alloys. In commercial alloys, it usually does not exceed $10 \mathrm{wt} \%$, since higher amounts negatively affect the alloy ductility [6]. In solid solution, $\mathrm{Al}$ incorporates into the $\mathrm{MgO} / \mathrm{MgOH}_{2}$ surface film, increasing the film's stability and ennobling the $\mathrm{Mg}$ matrix by $\sim 100 \mathrm{mV}$ [7]. Commercial cast $\mathrm{Mg}$-Al alloys usually show $\mathrm{Al}$ segregation within the $\alpha$-Mg matrix,

\footnotetext{
* Corresponding author.

E-mail address: beatrizmingo@ucm.es (B. Mingo).
} 
Table 1

$\mathrm{Fe} / \mathrm{Mn}$ tolerance limit for different $\mathrm{Mg}$ alloys.

\begin{tabular}{lll}
\hline Alloy & Fe/Mn tolerance limit & Reference \\
\hline AM50 & $0.0072-0.0101$ & {$[21]$} \\
AM60 & $0.007-0.232$ & {$[21]$} \\
Mg (gravity cast) & 0.036 & {$[22]$} \\
Mg (gravity cast) & 0.020 & {$[23]$} \\
AZ91 (gravity cast) & 0.032 & {$[24]$} \\
AZ91 (die cast) & 0.032 & {$[24,25]$} \\
AM60 (die cast) & 0.021 & {$[26]$} \\
AE42 (die cast) & 0.020 & {$[28]$} \\
AS41 (die cast) & 0.010 & \\
\hline
\end{tabular}

i.e. the $\mathrm{Al}$ content can vary from $1.5 \mathrm{wt} \%$ in the centre of the $\alpha-\mathrm{Mg}$ phase to $12 \mathrm{wt} \%$ in the matrix surrounding the eutectic $\beta$-phase $(\beta$ $\mathrm{Mg}_{17} \mathrm{Al}_{12}$ ) [8]. This may result in two phenomena: preferential corrosion at locations with low $\mathrm{Al}$ content [9] and less intense galvanic couples between the $\beta$-phase and the surrounding Al-rich matrix [10]. The influence of the $\beta$-phase on the overall corrosion behaviour of Mg$\mathrm{Al}$ alloys mainly depends on its relative proportion and morphology [10]. Recently it has been shown that the surface potential of the $\beta$ phase (and therefore its electrochemical activity) varies from $\sim 10 \mathrm{mV}$ [11] to $\sim 240 \mathrm{mV}$ [10] depending on its $\mathrm{Al}$ content and the composition of the surrounding matrix. Despite being a cathode, the $\beta$-phase may be able to act as a physical barrier, thereby decreasing the corrosion rate [12].

Most commercial Mg-Al alloys belong to the AM (Mg-Al-Mn) or AZ (Mg-Al-Zn) series. Their corrosion behaviour is drastically affected by the presence of impurities ( $\mathrm{Fe}, \mathrm{Ni}, \mathrm{Cu}$ and $\mathrm{Co}$ ) which lead to severe microgalvanic corrosion phenomena [13]. The tolerance limits of impurities vary with the manufacturing method [14] and alloy composition. For instance, it has been reported that the tolerance limit of $\mathrm{Ni}$ increases with the solidification rate [7]. Special attention is always given to $\mathrm{Fe}$, since $\mathrm{Mg}$ alloys are usually processed in steel crucibles [15]. Fe tolerance limit is greatly influenced by the Al content, which reduces the solubility of $\mathrm{Fe}$ in $\mathrm{Mg}$ [16] from $\sim 170 \mathrm{ppm}$ in pure $\mathrm{Mg}$ to $5 \mathrm{ppm}$ in alloys with $>7 \mathrm{wt} \% \mathrm{Al}$ [7]. Fe not only influences the corrosion resistance of $\mathrm{Mg}-\mathrm{Al}$ alloys, but also obstructs the grain refinement, diminishes the mechanical properties such as tensile strength, and hampers the formability [5]. In contrast to $\mathrm{Al}, \mathrm{Mn}$ increases the $\mathrm{Fe}$ tolerance limit in $\mathrm{Mg}$ alloys, greatly reducing its detrimental effect [16]. $\mathrm{Mn}$ is usually added to the melt in the form of $\mathrm{MnCl}_{2}$, which rapidly reacts forming $\mathrm{Al}_{5}(\mathrm{Mn}, \mathrm{Fe})_{2}$ and $\mathrm{Al}_{8}(\mathrm{Mn}, \mathrm{Fe})_{5}$ compounds at the bottom of the melt which are then removed $[17,18]$. The Fe remaining in the solution is also entrapped by $\mathrm{Mn}$ by the so-called scavenger effect, reducing considerably the potential difference between the Fe-rich particles and the $\alpha-\mathrm{Mg}$ matrix [19]. However, this beneficial effect becomes noticeable only if a critical $\mathrm{Fe} / \mathrm{Mn}$ ratio is achieved. This ratio usually lies at $\sim 0.032$ [20], but is not easily controllable, since it greatly depends on the alloy composition [5] (Table 1).

Apart from $\mathrm{Mn}$, there are other elements capable of retaining $\mathrm{Fe}$ impurities. Prasad [15] demonstrated that $\mathrm{Zr}$ was able to reduce the $\mathrm{Fe}$ content in cast binary Mg-X alloys (X: Y, Si, Sn, Ca, Sr, Ce, Gd, Nd, Li,
$\mathrm{La}, \mathrm{Mn}$, and $\mathrm{Zn}$ ) by forming $\mathrm{Fe}-\mathrm{Zr}$ compounds which were then deposited at the bottom of the crucible. $\mathrm{Wu}$ [29] found that $\mathrm{B}_{2} \mathrm{O}_{3}$ and $\mathrm{TiO}_{2}$ additions to cast AZ91 alloy also reduced the amount of Fe impurities; the efficiency of the purification was greater in case of $\mathrm{B}_{2} \mathrm{O}_{3}$. BFe compounds were identified in the sludge, while FeTi intermetallics were expected but could not be detected.

Cao and co-workers [30] carried out an extensive study about the influence of alloying elements ( $\mathrm{Mn}, \mathrm{Sn}, \mathrm{Ca}, \mathrm{Zn}, \mathrm{Al}, \mathrm{Zr}, \mathrm{Si}$ and $\mathrm{Sr}$ ) on corrosion behaviour of high purity magnesium. All the studied alloys had an Fe content below the tolerance limit to minimize its detrimental effect. It was found that all the alloying elements had a negative influence on the corrosion resistance due to the formation of secondary phases that promoted the formation of galvanic couples and accelerated the corrosion rates.

However, in commercial alloys (which are usually based on the Mg$\mathrm{Al}$ system), where the impurity levels are higher and alloying is required to improve the mechanical properties, the incorporation of minor quantities of specific elements may improve the overall performance of the alloy [31-33]. For instance, a previous work by the authors [34], shows that additions of $\mathrm{Nd}$ (up to $1 \mathrm{wt} \%$ ) to gravity cast AZ91 alloy reduces the corrosion rate by $\sim 95 \%$, due to the reduction of the intensity of galvanic coupling between the microconstituents. The addition of $\mathrm{Nd}$ results in the formation of $\mathrm{Al}-\mathrm{Mn}-\mathrm{Nd}\left(\mathrm{Al}_{8} \mathrm{Mn}_{4} \mathrm{Nd}\right)$ compounds which are electrochemically less active compared with $\mathrm{Al}_{8} \mathrm{Mn}_{5}$ intermetallics (present in the unmodified alloy) and the coupling phenomenon is, therefore, less severe. A similar behaviour is observed in extruded AZ91 and AM50 alloys with the incorporation of Gd (up to $1 \mathrm{wt} \%$ ) [9]. Minor additions of Y (0.9 wt\%) [35], Ce (0.92 wt\%) and La (0.66 wt\%) [36] to AZ91 alloy also produce a positive effect. In these cases, the beneficial influence is attributed to the incorporation of $\mathrm{Y}, \mathrm{Ce}$ and La to the layer of corrosion products.

Alkaline elements $\mathrm{Ca}$ and $\mathrm{Sr}$ are both used in commercial alloys (AJ62 and MRI230D) to improve creep resistance at high temperature $[37,38]$. Regarding the corrosion behaviour, it was noted that Ca-rich intermetallics, such as $\mathrm{Al}_{2} \mathrm{Ca}$, have a greater tendency to support the anodic reaction compared with $\mathrm{Mg}$; therefore, they act as sacrificial anodes, protecting the $\alpha$ - $\mathrm{Mg}$ matrix $[39,40]$. The addition of Sr leads to the formation of Al-Sr and $\mathrm{Mg}-\mathrm{Sr}\left(\mathrm{Al}_{4} \mathrm{Sr}, \mathrm{Mg}_{17} \mathrm{Sr}_{2}\right.$ and $\mathrm{Mg}_{2} \mathrm{Sr}$ ) [20] intermetallics which homogenize the distribution of the $\beta$-phase. Sr also improves the corrosion resistance of $\mathrm{Mg}-\mathrm{Al}$ alloys, ennobling their corrosion potential and decreasing the corrosion current density $[20,41]$. Combined with $\mathrm{Al}, \mathrm{Sr}$ enhances the ductility and decreases the crack formation during processing [42]. In regards to the addition of $\mathrm{Sn}$, precipitates of $\mathrm{Mg}_{2} \mathrm{Sn}$ are formed along the grain boundaries and increases the mechanical properties at ambient temperature through solid solution strengthening mechanisms [43].

The addition of low amounts of alloying elements allows the improvement of specific properties without increasing substantially the total price of the material, which is a key factor from the commercialization point of view. Most commercial Mg alloys, even high purity alloys [44], usually contain small amounts of $\mathrm{Mn}$ as an alloying element (as in the AM and AZ series) or as an impurity. Given the high dependency of the $\mathrm{Fe} / \mathrm{Mn}$ critical ratio on the alloy composition, it seems

Table 2

Chemical composition of studied alloys.

\begin{tabular}{|c|c|c|c|c|c|c|c|c|c|c|}
\hline \multicolumn{10}{|l|}{ Elements (wt\%) } & \multirow[t]{2}{*}{$\mathrm{Fe} / \mathrm{Mn}$} \\
\hline Alloy & $\mathrm{Al}$ & $\mathrm{Cu}$ & $\mathrm{Ni}$ & $\mathrm{Fe}$ & Mn & $\mathrm{Nd}$ & $\mathrm{Ca}$ & $\mathrm{Y}$ & Sn & \\
\hline Mg-9Al & 12.7 & 0.0003 & $<0.0002$ & 0.0155 & 0.0045 & - & - & - & - & 3.444 \\
\hline Mg-9Al-0.5Mn & 7.3 & 0.0005 & 0.0004 & 0.0110 & 0.4240 & - & - & - & - & 0.026 \\
\hline Mg9Al-0.25Nd & 7.0 & 0.0014 & $<0.0002$ & 0.0190 & 0.0030 & 0.25 & - & - & - & 6.333 \\
\hline Mg-9Al-0.5Ca & 8.7 & 0.0007 & $<0.0002$ & 0.0020 & 0.0235 & - & 0.31 & - & - & 0.085 \\
\hline Mg-9Al-0.5Y & 7.4 & 0.0019 & $<0.0002$ & 0.0071 & 0.0102 & - & - & 0.45 & - & 0.696 \\
\hline Mg-9Al-0.5Sn & 8.2 & 0.0010 & $<0.0002$ & 0.0077 & 0.0300 & - & - & - & 0.38 & 0.257 \\
\hline
\end{tabular}



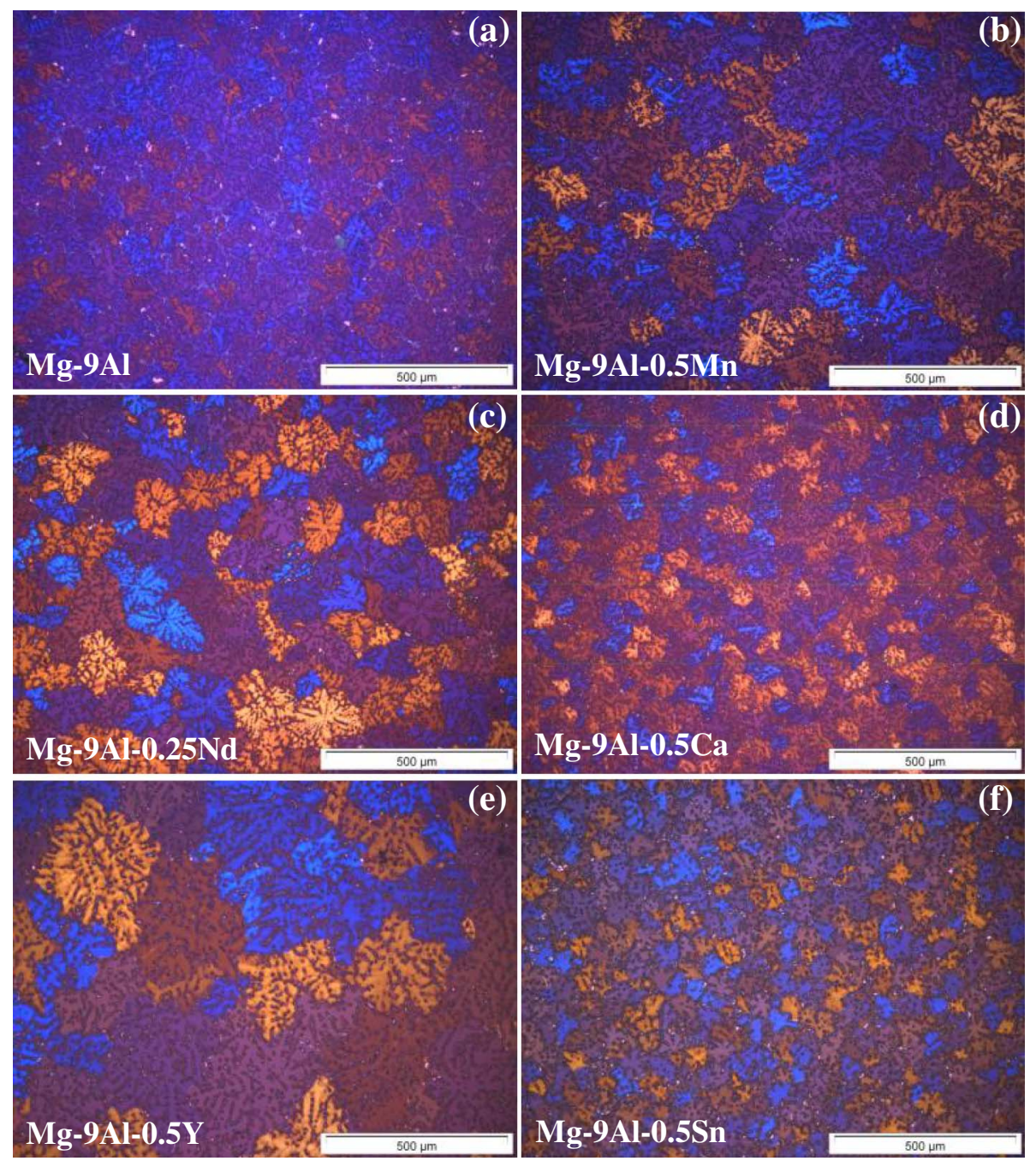

Fig. 1. Optical micrographs of (a) Mg-9Al, (b) Mg-9Al-0.5Mn, (c) Mg-9Al-0.25Nd, (d) Mg-9Al-0.5Ca, (e) Mg-9Al-0.5Y and (f) Mg-9Al-0.5Sn alloys.

necessary to study further the influence of alloying elements in those alloys where the critical $\mathrm{Fe} / \mathrm{Mn}$ ratio which determines the corrosion tolerance limit of the alloy, is not reached (Table 2). In such cases the influence of the alloying elements can be elucidated without Mn masking their effect. In the present work, the influence of minor alloying additions ( $\mathrm{Nd}, \mathrm{Y}, \mathrm{Ca}$ and $\mathrm{Sn}$ ) on microstructure and corrosion behaviour of cast Mg-9Al alloy is studied, using a Mn-containing Mg9Al alloy as a reference. Secondary phases are characterized by EPMA (Electron Probe Micro-Analysis) and quantified by image analysis. Special interest is given to the study of galvanic coupling phenomenon between microconstituents by measuring their surface potential difference using a localized electrochemical technique (Scanning Kelvin Probe Force Microscopy). The electrochemical behaviour of the phases is correlated to the overall corrosion resistance of the alloy calculated from hydrogen collection measurements and potentiodynamic polarization tests.

\section{Experimental part}

\subsection{Test materials}

Gravity cast Mg-Al alloys were provided by the Magnesium Innovation Centre (Helmholtz Zentrum Geesthacht, Germany). The Mg alloys were permanent mould gravity cast using a finger mould of $18 \mathrm{~mm}$ diameter. $\mathrm{Mg}$ was molten under protective atmosphere of $\mathrm{Ar}$ with $0.2 \mathrm{vol} \% \mathrm{SF}_{6}$ and held at $680{ }^{\circ} \mathrm{C}$, where the alloy additions were added as elemental additions, except for $\mathrm{Y}$ which was added in the form of Mg-15Y master alloy. The molten alloy was mixed during $5 \mathrm{~min}$ to ensure homogeneity and then poured into the mould. The chemical composition (Table 2) was analysed using spark optical emission spectroscopy (Spectrolab, Spectro, Kleve) for Al, Y, Fe, Cu, N and X-ray fluorescence analysis (Bruker S5 X-ray fluorescence spectrometer) for $\mathrm{Ca}$ and Sn. $4 \mathrm{~mm}$-thick specimens were cut from $15 \mathrm{~mm}$-diameter cylindrical ingots.

Metallographic characterization of the materials was carried out in polished specimens $(0.1 \mu \mathrm{m}$ diamond paste). Acetic-picral reagent $(5 \mathrm{~g}$ picric acid, $7 \mathrm{~mL}$ acetic acid, $10 \mathrm{~mL}$ distilled water and $140 \mathrm{~mL}$ ethanol) was used to reveal the grains and nital reagent $(5 \mathrm{~mL}$ nitric acid and $95 \mathrm{~mL}$ ethanol) was used to reveal the microconstituents. Specimens were examined by optical microscopy (OM) using a Leica DMI 5000 instrument and scanning electron microscopy (SEM) using a JEOL JSM6400 microscope equipped with Oxford Link energy dispersive X-ray (EDS) microanalysis spectrometer. Grain size was analysed following the ASTM E112-12 standard using the linear intercepts method: randomly distributed straight lines were drawn on a micrograph and the number of grains intercepted by the lines was counted. The lines were long enough to yield at least 50 intercepts. X-ray diffraction (XRD) was used for phase identification using a Philips X'Pert diffractometer $\left(\mathrm{CuK}_{\alpha}=0.154056 \mathrm{~nm}\right)$. The XRD patterns were registered for $2 \theta$ values between $10^{\circ}$ and $90^{\circ}$ (step size 0.04 and time per step $5 \mathrm{~s}$ ) and evaluated using PANalytical's X'PertHighScore software (ICDD PDF$4+$ ). Phase composition and distribution were also examined by 
Table 3

Vickers hardness and grain size of the alloys investigated.

\begin{tabular}{lll}
\hline Alloy & $\mathrm{HV}_{5}$ & Grainsize $(\mu \mathrm{m})$ \\
\hline Mg-9Al & $108 \pm 3$ & $66 \pm 7$ \\
Mg-9Al-0.5Mn & $87 \pm 5$ & $115 \pm 19$ \\
Mg-9Al-0.25Nd & $87 \pm 2$ & $102 \pm 11$ \\
Mg-9Al-0.5Ca & $80 \pm 6$ & $57 \pm 3$ \\
Mg-9Al-0.5Y & $74 \pm 7$ & $220 \pm 20$ \\
Mg-9Al-0.5Sn & $79 \pm 6$ & $53 \pm 4$ \\
\hline
\end{tabular}

electron microprobe analysis (EPMA) using a JEOL JXA-8900 M WD/ ED microscope. Quantification of secondary phases was performed by image analysis using five SEM micrographs taken at $\times 300$ magnification which were analysed with the ImageJ software. The hardness was measured on ground specimens with an AVK-AП Vickers hardness tester using a load of $5 \mathrm{~kg}$ for $20 \mathrm{~s}$. The average of fifteen measurements was calculated for each specimen. Surface potential (also known as Volta potential) maps were acquired on polished specimens using a NanoscopeIIIaMultiMode scanning Kelvin probe force microscope (SKPFM, Veeco-Digital Instruments) with a Pt-coated $(20 \mathrm{~nm}) \mathrm{Si}$ tip working in tapping mode and keeping the tip-to-sample distance constant at $100 \mathrm{~nm}$ [10]. Temperature $\left(22^{\circ} \mathrm{C}\right)$ and relative humidity (40-65\%) were maintained constant during the measurements.

\subsection{Corrosion tests}

Hydrogen measurements were carried out during 3 days of immersion at $22{ }^{\circ} \mathrm{C}$ in naturally-aerated $0.5 \mathrm{wt} \% \mathrm{NaCl}$ solution, using ground specimens $\left(\sim 1 \mathrm{~cm}^{2}\right)$. Although corrosion tests are usually carried out in $3.5 \mathrm{wt} \% \mathrm{NaCl}$, which simulate the salt concentration of sea water, this environment is too aggressive for magnesium alloys; corrosion progresses so fast that there is no possibility to study its evolution with time. For this reason, a lower concentration of $\mathrm{NaCl}$ was chosen to carry out the investigation. The corrosion rates were calculated using Eq. (1) [45]:

$P=\frac{1.085 V_{\mathrm{H}_{2}}}{\mathrm{~A} \mathrm{t}}$

where $P\left(\mathrm{mg} \mathrm{cm}^{-2} \mathrm{~d}^{-1}\right)$ represents the corrosion rate, $V_{\mathrm{H}_{2}}(\mathrm{~mL})$ is the measured hydrogen volume evolved in the cathodic reaction, $\mathrm{A}\left(\mathrm{cm}^{2}\right)$ is the exposed area and $t$ (days) represents the exposure time. The experimental set-up used for measuring the $\mathrm{H}_{2}$ is described in [46].

Potentiodynamic polarization measurements were performed after $1 \mathrm{~h}$ of immersion in naturally-aerated $0.5 \mathrm{wt} \% \mathrm{NaCl}$ solution using a three-electrode cell connected to computer-controlled potentiostat (GillAC, ACM Instruments). The test material $\left(\sim 1 \mathrm{~cm}^{2}\right)$ served as working electrode and graphite and silver/silver chloride (Ag/AgCl-3M $\mathrm{KCl})$ electrodes were used as the counter and reference electrodes, respectively. The cathodic and anodic branches of the polarization curves were obtained separately using a scanning rate of $0.3 \mathrm{mV} / \mathrm{s}$. The cathodic branch was measured starting from $-150 \mathrm{mV}$ vs. the open circuit potential (OCP) and the anodic branch from the OCP until a maximum current of $5 \mathrm{~mA} / \mathrm{cm}^{2}$. Measurements were performed by triplicate. The current densities were calculated by Tafel extrapolation of the cathodic branch.

\section{Results}

\subsection{Characterization}

The optical micrographs of the investigated alloys reveal the dendritic grain microstructure (Fig. 1). There is little influence of the alloying elements on the hardness, while their influence on the grain size is more pronounced (Table 3 ).

Ca- and Sn-modified alloys present a smaller grain size compared to the rest of the studied alloys. This result was expected since Ca and Sn have already been used as grain refiners in Mg based alloys [47]. These elements promote compositional segregation [48] that results in the formation of $\mathrm{Ca}$ and $\mathrm{Sn}$-rich intermetallics at the grain boundary which are responsible for the grain refinement [49].

The unmodified Mg-9Al alloy shows a dendritic $\alpha$-Mg matrix and a partially divorced eutectic $\alpha-\mathrm{Mg}_{\text {eut }} / \beta-\mathrm{Mg}_{17} \mathrm{Al}_{12}$ formed at the interdendritic regions as a result of non-equilibrium solidification during casting. High cooling rates during the solidification of the alloy promote Al segregation within the remaining liquid phase, which eventually achieves the eutectic composition and results in the formation of the eutectic $\beta$-phase. $\mathrm{Al}-\mathrm{Fe}(\mathrm{Mn})$ intermetallic particles are also observed in the interdendritic regions (Fig. 2a). SEM/EDS/XRD/EPMA studies reveal that the addition of $\mathrm{Mn}, \mathrm{Nd}$ and $\mathrm{Y}$ does not affect neither the composition and morphology of the $\alpha$-Mg matrix nor the $\beta$-phase, but they do modify the intermetallic particles forming Al-Mn-Fe, Al-Fe-Nd (Mn), Al-Nd, Al-Y-Fe(Mn) and $\mathrm{Al}_{2} \mathrm{Y}$ (Fig. 2). $\mathrm{Al}_{2} \mathrm{Y}$ intermetallic was the only one detected by XRD analysis (Fig. 3), the others were identified through compositional analysis using EDS. Mn, Nd and $\mathrm{Y}$ tend to be incorporated into Al-rich secondary phases with both high and small amounts of Fe (Fig. 2).

As for the Mg-9Al-0.5Ca alloy, although Al-rich intermetallic particles containing some $\mathrm{Fe}(\mathrm{Al}-\mathrm{Fe}-\mathrm{Ca}(\mathrm{Mn}))$ were disclosed, the most interesting fact was the incorporation of $\mathrm{Ca}$ into the $\beta$-phase $(\sim 1.7$ at.\% Ca, Fig. 4a) $[50,51]$ and greater area fraction of this phase compared to the rest of the studied alloys (Table 4). It is worth mentioning that no $\mathrm{Al}_{2} \mathrm{Ca}$ particles were detected despite being common in Ca-modified $\mathrm{Mg}-\mathrm{Al}$ alloys [49]. Their formation mainly depends on the $\mathrm{Ca} / \mathrm{Al}$ ratio [52] and the thermal history of the alloy. For instance, Suzuki [52] reported that after annealing of the Mg-Al-Ca alloy, the $(\mathrm{Mg}, \mathrm{Al})_{2} \mathrm{Ca}$ phase transformed to $\mathrm{Al}_{2} \mathrm{Ca}$ by a shear-assisted mechanism.

Regarding Sn addition, some authors [47] have observed that Sn tends to be associated with the $\beta$-phase in the form of $\mathrm{Mg}_{2} \mathrm{Sn}$ particles that act as heterogeneous nucleation cores responsible for the microstructure refinement. The reduced free energy barrier on $\mathrm{Mg}_{2} \mathrm{Sn}$ surface promotes the nucleation of the $\beta$-phase at the locations of the particles. This leads to a higher number of nucleation cores that results in the formation of a refined and dispersed $\beta$-phase that hampers the grain growth. In the present study, $\sim 0.2$ at. $\%$ of $S n$ was identified within the $\beta$-phase of Mg-9Al-0.5Sn alloy, presumably in the form of $\mathrm{Mg}_{2} \mathrm{Sn}$ (Fig. 4b) which remains to be confirmed by TEM in further studies. Low amounts of Al-Mn-Fe-Sn inclusions were also observed at the interdendritic regions.

Image analysis of the studied alloys was carried out with quantitative purposes and the area fractions of the different microconstituents were calculated (Table 4). It was observed that the $\beta$-phase area fraction is considerably greater in $\mathrm{Mg}$-9Al compared with the rest of the alloys, which is attributable to its higher $\mathrm{Al}$ content. $\mathrm{Mg}-9 \mathrm{Al}-0.5 \mathrm{Ca}$ and Mg-9Al-0.5Sn alloys exhibit a greater area fraction of $\beta$-phase than $\mathrm{Mg}$ 9Al-0.5Mn, Mg-9Al-0.5Y and Mg-9Al-0.25Nd. This is due to the slightly greater $\mathrm{Al}$ content in Ca- and Sn-containing alloys and the enhanced compositional segregation caused by these elements. The area fraction of Al-rich inclusions (not including the $\beta$-phase) varies depending on $\mathrm{Fe}$ impurity levels and concentration of the added alloying elements. For instance, $\mathrm{Mg}-9 \mathrm{Al}-0.5 \mathrm{Mn}$ and $\mathrm{Mg}-9 \mathrm{Al}-0.5 \mathrm{Y}$ show the greatest area fraction of these intermetallics, which is a result of the slightly greater amount of $\mathrm{Mn}$ and $\mathrm{Y}(0.42$ and $0.45 \mathrm{wt} \%$, respectively) compared to the rest of the alloys $(0.25 \mathrm{Nd}, 0.31 \mathrm{Ca}$ and $0.38 \mathrm{Sn}$, wt\%). Mg-9Al-0.5Ca alloy, on the other hand, has the smallest area fraction of Al-rich intermetallics, which can be explained by lower amount of Fe in the alloy composition.

\subsection{Surface potential measurements}

Surface potential maps of the microconstituents in the alloys were obtained using SKPFM (Figs. 5 and 6). The $\beta$-phase shows different 

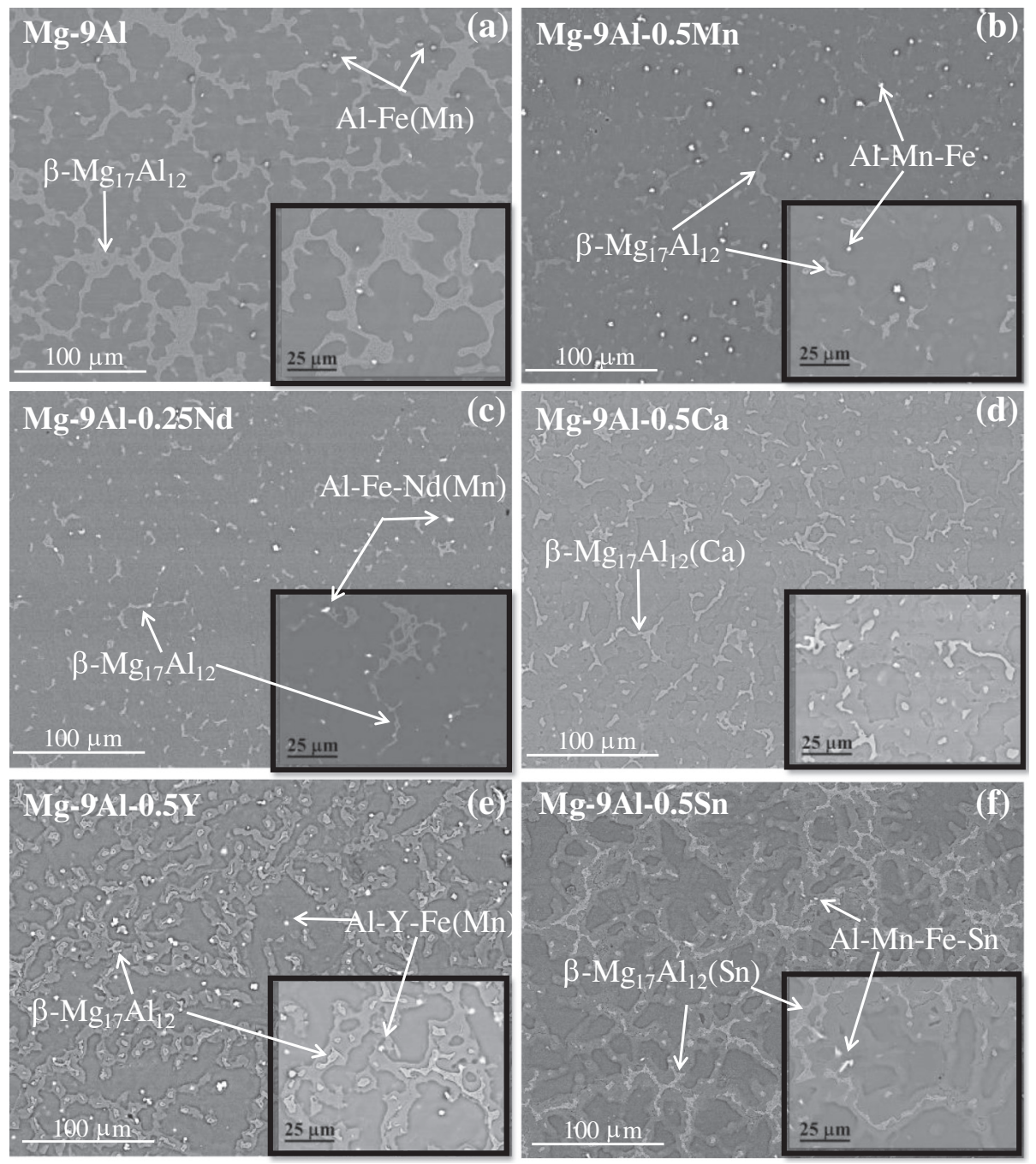

Fig. 2. SEM micrographs of (a) Mg-9Al, (b) Mg-9Al-0.5Mn, (c) Mg-9Al-0.25Nd, (d) Mg-9Al-0.5Ca, (e) Mg-9Al-0.5Y and (f) Mg-9Al-0.5Sn alloys.

potential values depending on the alloy. In Mg-9Al, Mg-9Al-0.5Mn, Mg9Al-0.25Nd and Mg-9Al-0.5Y alloys the $\beta$-phase behaves similarly $(35-70 \mathrm{mV}$ ) with respect the $\alpha-\mathrm{Mg}$ matrix. In $\mathrm{Mg}-9 \mathrm{Al}-0.5 \mathrm{Ca}$ and $\mathrm{Mg}-$ 9Al-0.5Sn alloys it shows a lower $(25 \mathrm{mV})$ and higher $(90-100 \mathrm{mV}$ ) potential difference with the matrix, respectively (Table 5 ). This is related to $\mathrm{Ca}$ and $\mathrm{Sn}$ incorporation into the $\beta$-phase: the more active nature of $\mathrm{Ca}$ (compared with $\mathrm{Al}$ and $\mathrm{Mg}$ ) tends to decrease the potential difference, while nobler $S n$ tends to increase it.

Surface potential maps of Al-rich intermetallics and their profiles are presented in Fig. 6 . All secondary phases are cathodic with respect to the $\alpha-\mathrm{Mg}$ matrix and their surface potential values mainly depend on the Fe level (Table 5). The highest potentials $(250-700 \mathrm{mV}$ ) are

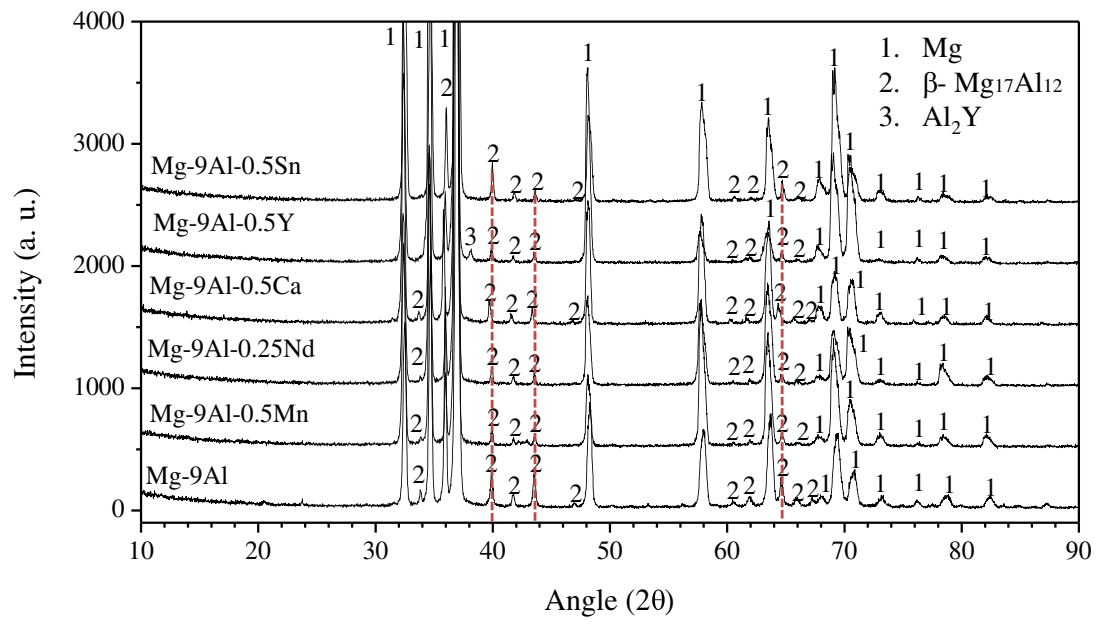

Fig. 3. X-ray diffraction patterns of the studied magnesium alloys. 

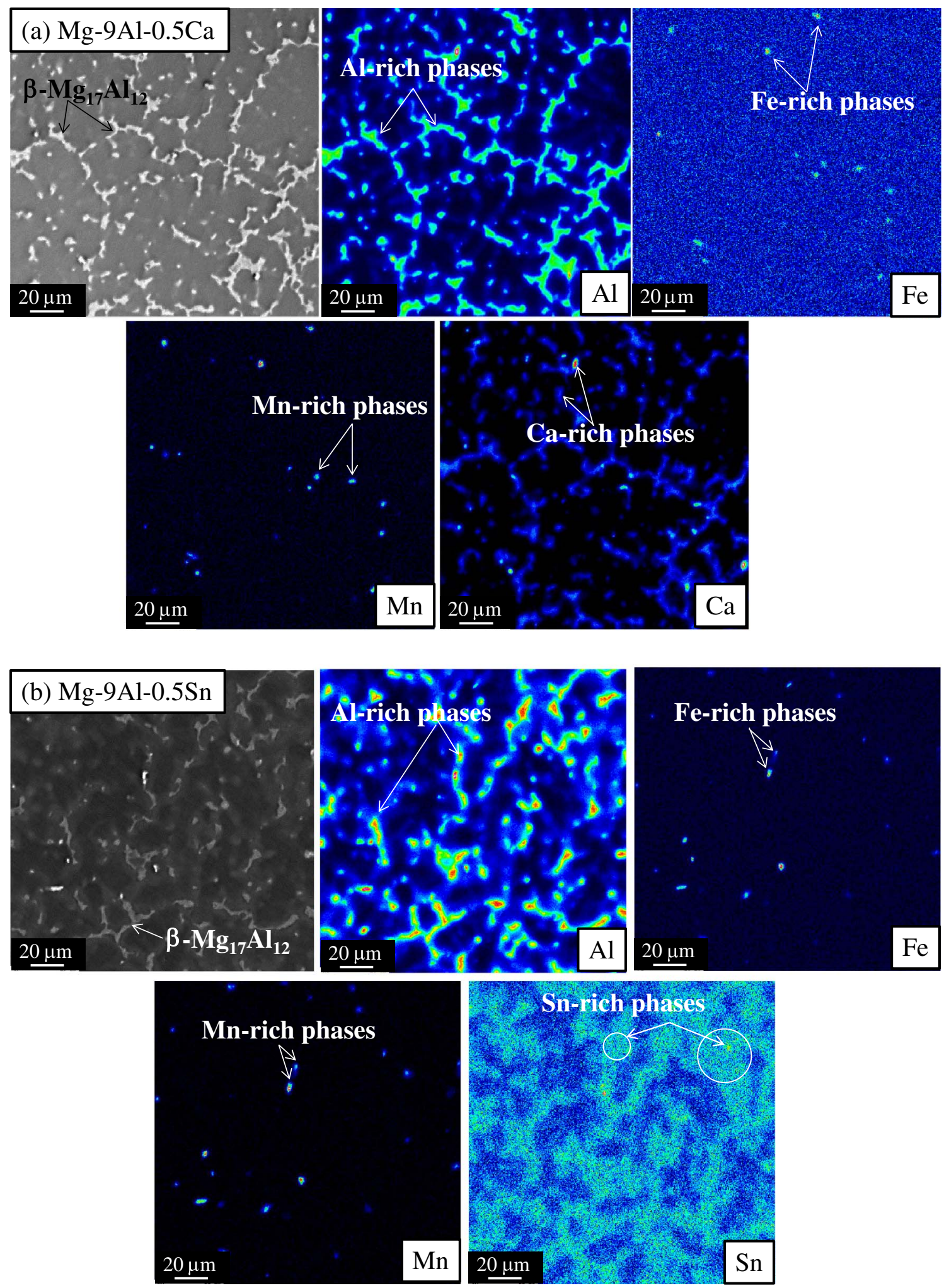

Fig. 4. EMPA maps of (a) Mg-9Al-0.5Ca and (b) Mg-9Al-0.5Sn alloys.

observed for the Fe-rich particles in the unmodified alloy Mg-9Al. When these particles are modified with minor quantities of alloying elements, the potential difference decreases. In case of Mg-9Al-0.5Mn, values of $120-290 \mathrm{mV}$ are observed depending on the Fe content. In Mg-9Al$0.25 \mathrm{Nd}$ three types of Nd-containing particles are found; their surface potential values ( $90-220 \mathrm{mV}$ ) increase with the Fe content and decrease with the Nd content. Al-Nd particles show a relatively low potential difference of $\sim 100 \mathrm{mV}$ compared with Fe-rich particles. It is worth noting that $\mathrm{Al}-\mathrm{Fe}(\mathrm{Mn})$ intermetallics similar to the ones observed in the unmodified alloy were identified in the microstructure; most likely, the amount of Nd added to the melt was not sufficient to avoid their formation. The addition of $\mathrm{Y}$ leads to similar results since it reduces the potential difference of Fe-rich intermetallics; the newly formed $\mathrm{Al}_{2} \mathrm{Y}$ phase also shows a cathodic behaviour with a potential difference value 
Table 4

Quantitative image analysis (area fraction) of the main microconstituents.

\begin{tabular}{lll}
\hline Alloy & B-phase (\%) & Al-rich intermetallics (\%) \\
\hline Mg-9Al & $19.8 \pm 1.3$ & $0.10 \pm 0.03$ \\
Mg-9Al-0.5Mn & $5.5 \pm 0.8$ & $0.44 \pm 0.03$ \\
Mg-9Al-0.25Nd & $3.8 \pm 0.5$ & $0.13 \pm 0.04$ \\
Mg-9Al-0.5Ca & $9.1 \pm 1.6$ & $0.021 \pm 0.001$ \\
Mg-9Al-0.5Y & $6.2 \pm 1.4$ & $0.33 \pm 0.03$ \\
Mg-9Al-0.5Sn & $7.8 \pm 0.7$ & $0.054 \pm 0.016$ \\
\hline
\end{tabular}

of $60-90 \mathrm{mV}$.

Despite the small relative amount of intermetallics formed in $\mathrm{Mg}$ 9Al-0.5Ca it was possible to measure their potential with respect to the $\alpha$-Mg. Al-Fe- $\mathrm{Ca}(\mathrm{Mn})$ intermetallic was the Fe-containing phase with the lowest potential difference $(<80 \mathrm{mV})$ amongst the investigated alloys. This is attributable to the active nature of Ca which counterbalances the cathodic behaviour of Fe. In Mg-9Al-Sn it was expected that Sn would increase the potential difference of the intermetallics, since it presents a nobler behaviour than Fe; however, that was not the case, probably due to the low amount of Sn.

\subsection{Corrosion measurements}

Fig. 7 shows the hydrogen evolved from the cathodic reaction as a function of immersion time and examples of the surface appearance after the test. All studied alloys present linear kinetics over the entire experimental time and lower corrosion rates compared with the unmodified alloy Mg-9Al (Table 6). The improvement is greater in case of $\mathrm{Mn}, \mathrm{Ca}$ and $\mathrm{Y}$ additions.

The SEM analysis of corroded surfaces (not included here) provided information on the morphology of corrosion advance. The corrosion morphology of Mg-Al is typically localized [10], but, unlike in aluminium, where deep pits are formed, the corrosion progresses laterally due to the alkalinisation at the tips of the pits, which prevents deep pit penetration [4]. However, in the present work, little influence of the alloying elements on the corrosion morphology was observed.

Potentiodynamic polarization curves after $1 \mathrm{~h}$ of immersion in $0.5 \mathrm{wt} \% \mathrm{NaCl}$ are shown in Fig. 8. The unmodified alloy Mg-9Al presents a corrosion potential $\left(E_{\mathrm{corr}}\right)$ of $-1.47 \mathrm{~V}_{\mathrm{Ag} / \mathrm{AgCl}}$; the proximity of this value to the breakdown potential results in localized corrosion phenomenon manifested as a rapid increase of the anodic current density [46]. The incorporation of alloying elements in all cases results in a slight decrease in the $E_{\text {corr }}$; little changes can be observed in the anodic current density, except in the case of Mn where a slight tendency to passivation is observed. In contrast, there is a clear positive effect of alloying on cathodic kinetics: the cathodic branch is shifted to smaller current densities. This indicates that the corrosion process is cathodically controlled. Corrosion current densities $\left(i_{\text {corr }}\right)$ calculated from Tafel extrapolation of the cathodic branch show the same corrosion ranking of the alloys as the one observed in hydrogen collection measurements.

\section{Discussion}

The addition of minor alloying elements to $\mathrm{Mg}-9 \mathrm{Al}$ alloy results in significant changes in its microstructure and corrosion behaviour. Mn, $\mathrm{Nd}$ and $\mathrm{Y}$ are incorporated into Al-rich inclusions without affecting neither the morphology nor the composition of the $\beta$-phase. These inclusions also contain varying amounts of $\mathrm{Fe}$, the highest amount found in Nd-modified alloy followed by Y-modified one. The preferential incorporation of alloying elements into $\mathrm{Al}$ - and Fe-rich particles has previously been observed. In case of $\mathrm{Mn}$, this behaviour is widely known and has been reported repeatedly [25]. Several rare earths have also shown a similar behaviour. For instance, Yang [53,54] studied the effect of Ce and Nd additions to AZ91 alloy and observed the formation of Mg-Al-Mn-Ce-Fe and Mg-Al-Mn-Nd inclusions, respectively. Braszczyńska-Malik evaluated the influence of Ce-rich mish-metal additions to magnesium alloys and also identified the rare earths associated with $\mathrm{Fe}$ rich particles $\left(\mathrm{RE}_{2} \mathrm{Fe}_{14} \mathrm{Si}_{3}\right)$.

$\mathrm{Ca}$ and $\mathrm{Sn}$ are incorporated both into Al- and Fe-rich intermetallics and the $\beta$-phase, yielding a smaller grain size. However, the mechanism of incorporation into the $\beta$-phase seems to be different in each case. Ca is probably incorporated into the $\beta$-phase structure replacing some $\mathrm{Al}$ and $\mathrm{Mg}$ atoms as it can be deduced from the slight shifting of the $\beta$ phase diffraction peaks (Fig. 3 marked with a red line) towards lower $2 \theta$ values. $(\mathrm{Al}, \mathrm{Mg})_{2} \mathrm{Ca}$ may also form [55], but was not detected in the present study. On the contrary, Sn possibly forms $\mathrm{Mg}_{2} \mathrm{Sn}$ intermetallics [56] which are located within the $\beta$-phase. According to Doernberg [57], the solubility of $\mathrm{Sn}$ in the $\beta$-phase is insignificant and the $\beta$-phase peaks in the XRD pattern were not shifted, which also suggests that the ternary solubility of $\mathrm{Sn}$ in the $\beta$-phase is reduced. She [58] also identified spherical $\mathrm{Mg}_{2} \mathrm{Sn}$ particles with $180-580 \mathrm{~nm}$ diameter in an asextruded Mg-9Al-5Sn-0.3Mn alloy.

The compositional modification of secondary phases affects their surface potential difference with respect the $\alpha$-Mg matrix, which is directly related to microgalvanic corrosion. The addition of $\mathrm{Mn}, \mathrm{Nd}$ and $\mathrm{Y}$ diminishes the potential differences of $\mathrm{Al}$ - and Fe-rich intermetallics (Table 5) and improves the corrosion behaviour. The surface potential values of Al-Mn-Fe found in $\mathrm{Mg}-9 \mathrm{Al}-0.5 \mathrm{Mn}$ are similar to the ones obtained by Andreatta [59] in extruded AZ80 alloy, by Jönsson [60] in as cast AZ91D alloy and Ben-Hamu [61] in welded AZ31 alloy. The latter observed certain deviations in the surface potential difference values and also ascribed them to changes in the $\mathrm{Mn}$ and $\mathrm{Fe}$ content within the particles. In a previous work by the authors, a comparable decrease in the surface potential value was observed for Al-Mn-Nd(Fe) intermetallics in as cast AZ91 alloy with $0.3-1.5 \mathrm{wt} \% \mathrm{Nd}$ [34]. Jia [35] reported an increase in the potential difference between Al-Mn-Y inclusion and the $\alpha-\mathrm{Mg}$ matrix in as cast AZ91 alloy with $0.9 \mathrm{wt} \% \mathrm{Y}$. In the present work, the opposite behaviour was observed. $\mathrm{Y}$ is a very active rare earth with a standard reduction potential of $-2.38 \mathrm{~V}$, which is lower than that of $\mathrm{Al}(-1.677 \mathrm{~V}), \mathrm{Mn}(-1.182 \mathrm{~V})$ and $\mathrm{Fe}(-0.44 \mathrm{~V})$. This means that the increase in the surface potential value cannot be related to the presence of $\mathrm{Y}$; it is more likely to be associated with a higher amount of Fe impurities.

Corrosion studies show a positive response following the addition of
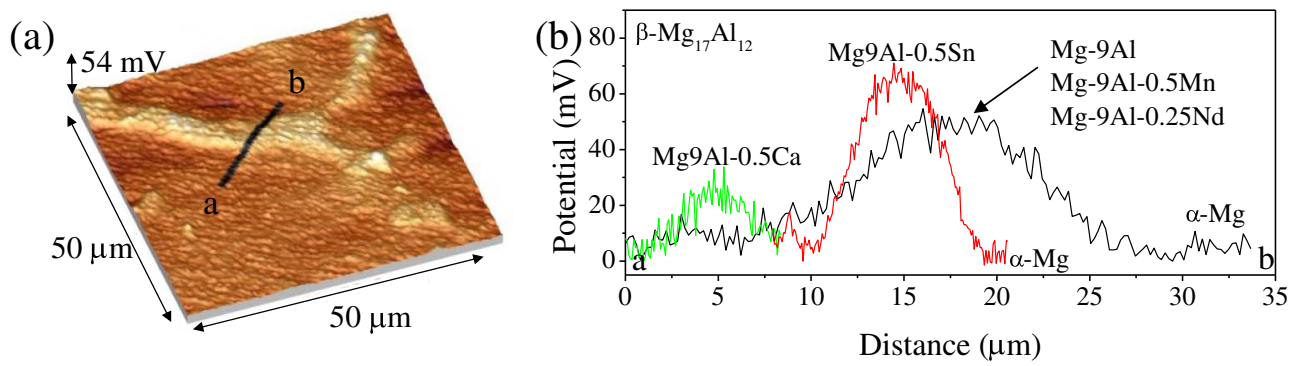

Fig. 5. (a) Surface potential map of Mg-9Al alloy; (b) comparison of $\beta$-phase surface profile in the investigated alloys. 
(a)

(d)
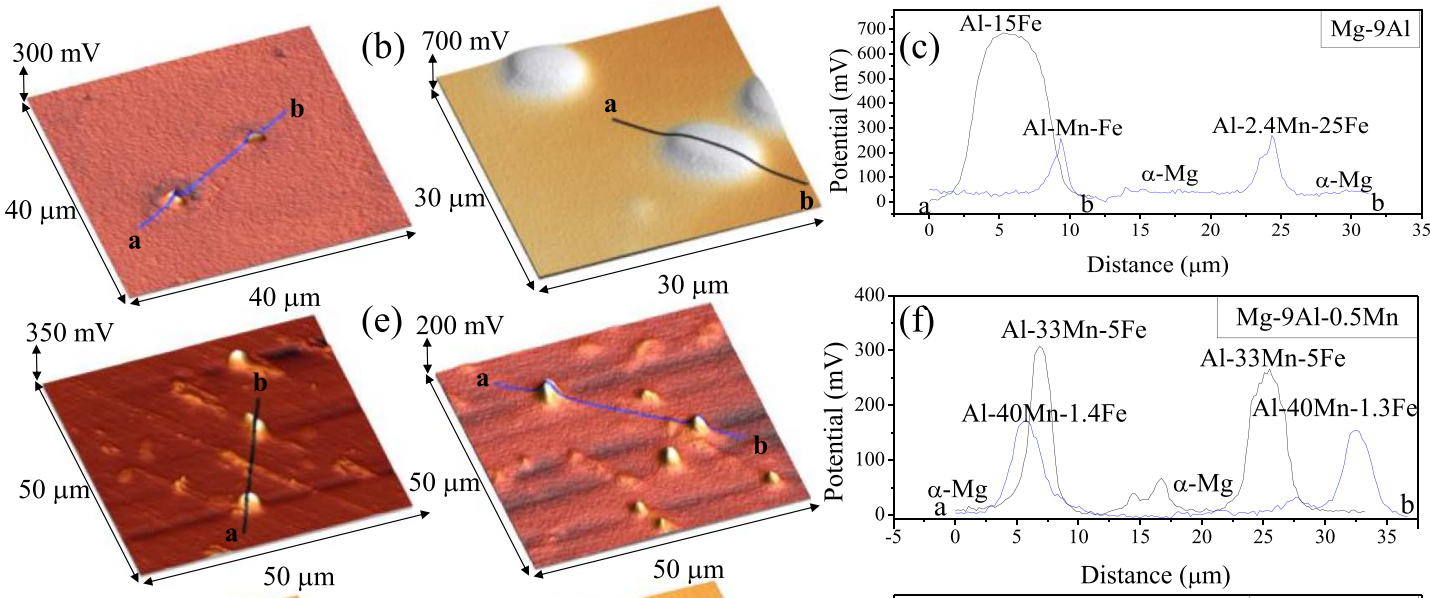

(g)

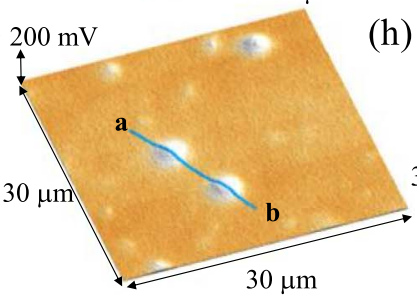

$400 \mathrm{mV}$
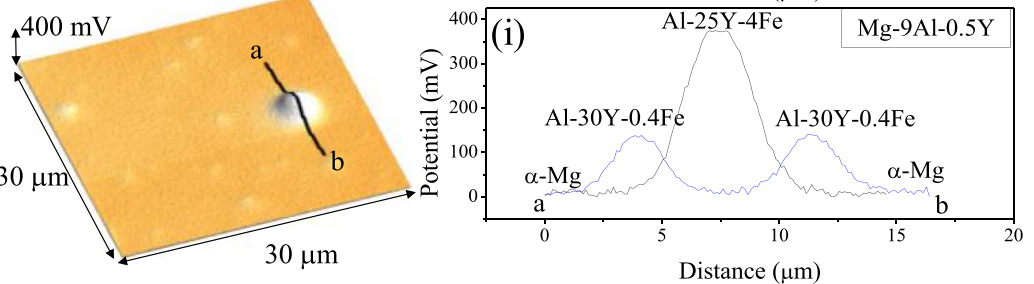

(j)
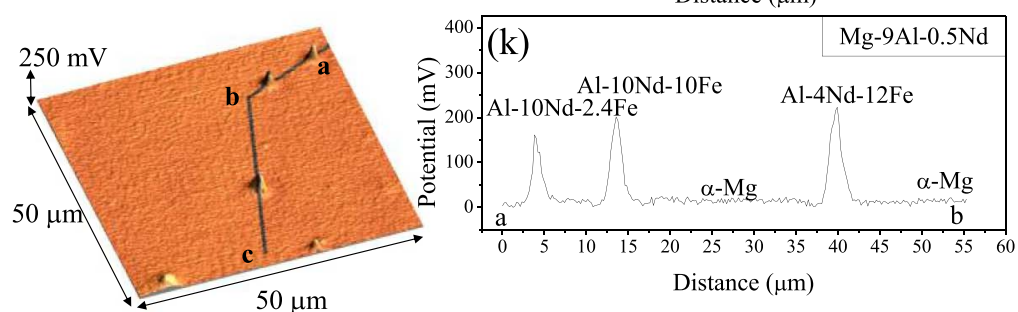

(1)
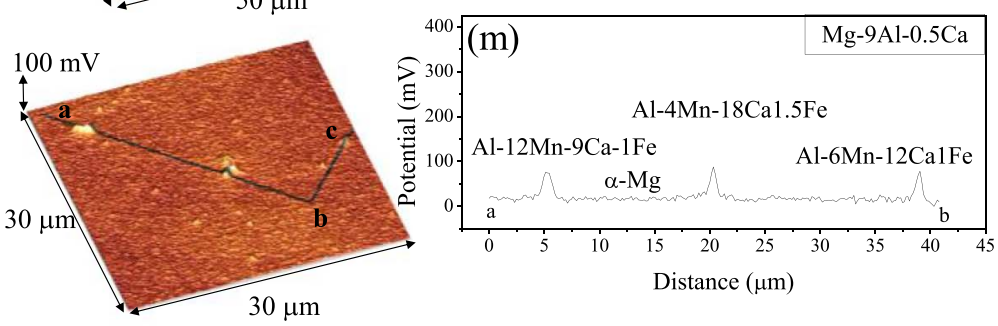

(n)
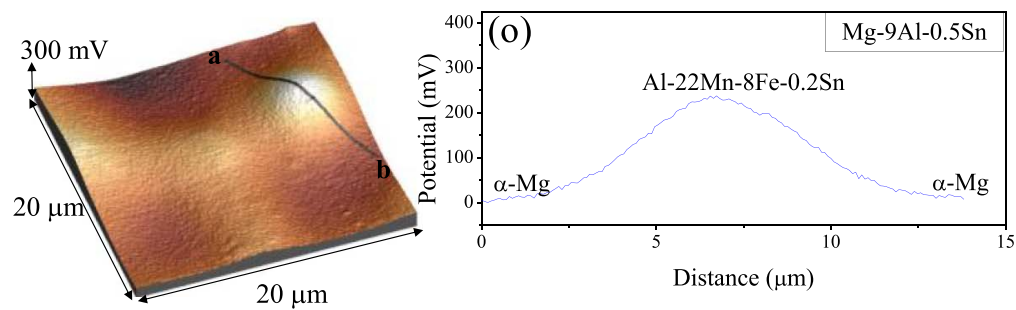

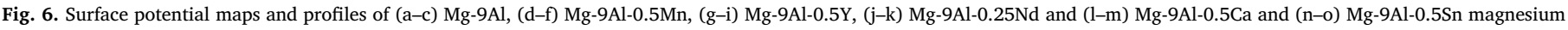
alloys.

Mn and Y, however the Nd effect is less impressive due to its lower content compared with other additions. The positive influence of $\mathrm{Mn}$ and $\mathrm{Y}$ can be observed in the lower corrosion rates calculated from hydrogen collection tests and lower cathodic kinetics in the potentiodynamic measurements. The slightly higher corrosion rate of Mg-9Al$0.5 \mathrm{Y}$ compared with $\mathrm{Mg}-9 \mathrm{Al}-0.5 \mathrm{Mn}$ is attributed to the higher relative amount of Fe in Al-rich intermetallics of the former (Table 5). The scarce influence of $\mathrm{Nd}$ on the corrosion rate is associated with the low amount of Nd present in the alloy; as a result, the Fe-rich particles are Nd-free and extremely harmful from a corrosion point of view. Following our previous studies, it is reasonable to expect that higher additions of $\mathrm{Nd}$, sufficient to ensure its incorporation to all Fe-rich intermetallics, would result in a considerable improvement of the corrosion resistance [34].

The improvement in the corrosion resistance in case of $\mathrm{Mn}, \mathrm{Y}$ and $\mathrm{Nd}$ additions is mainly associated with the reduction of the intensity of galvanic couples formed between Fe-rich intermetallics and the $\alpha-\mathrm{Mg}$ matrix, which can be clearly observed in the lower kinetics of the cathodic branch of the polarization curves. The Mn capacity to retain Fe impurities is widely known; the findings of this work indicate that $Y$ and $\mathrm{Nd}$ are also able to decrease the detrimental effect of Fe. Some authors believe that the positive influence of rare earth additions is mainly related to their incorporation into the semi-protective corrosion products layer $[35,36,62]$. However, our previous XPS study revealed 
Table 5

Phase composition and surface potential difference of microconstituents with respect to the $\alpha-\mathrm{Mg}$ matrix.

\begin{tabular}{|c|c|c|c|}
\hline Alloy & Phase & Phase composition (at.\%) & $\Delta \mathrm{V}(\mathrm{mV})$ \\
\hline \multirow[t]{2}{*}{ Mg-9Al } & $\beta-\mathrm{Mg}_{17} \mathrm{Al}_{12}$ & & $35-70$ \\
\hline & $\mathrm{Al}-\mathrm{Fe}(\mathrm{Mn})$ & $\mathrm{Al}-(16-27) \mathrm{Fe}(0-5.5) \mathrm{Mn}$ & $250-700$ \\
\hline \multirow[t]{3}{*}{ Mg-9Al-0.5Mn } & $\beta-\mathrm{Mg}_{17} \mathrm{Al}_{12}$ & & $35-70$ \\
\hline & Al-Mn-Fe & $\mathrm{Al}-(38-39) \mathrm{Mn}-(1.2-1.5) \mathrm{Fe}$ & $120-170$ \\
\hline & & $\mathrm{Al}-33 \mathrm{Mn}-5 \mathrm{Fe}$ & $270-290$ \\
\hline \multirow{4}{*}{$\begin{array}{l}\text { Mg-9Al- } \\
0.25 \mathrm{Nd}\end{array}$} & $\beta-\mathrm{Mg}_{17} \mathrm{Al}_{12}$ & & $35-70$ \\
\hline & $\mathrm{Al}-\mathrm{Fe}-\mathrm{Nd}(\mathrm{Mn})$ & $\mathrm{Al}-(2-10) \mathrm{Fe}-10 \mathrm{Nd}$ & $180-200$ \\
\hline & & $\begin{array}{l}\mathrm{Al}-(12-30) \mathrm{Fe}(4-6) \mathrm{Nd}- \\
(1.8-2.3) \mathrm{Mn}\end{array}$ & $150-220$ \\
\hline & Al-Nd & $\mathrm{Al}-(6-13) \mathrm{Nd}$ & $90-110$ \\
\hline \multirow[t]{3}{*}{$\mathrm{Mg}-9 \mathrm{Al}-0.5 \mathrm{Y}$} & $\beta-\mathrm{Mg}_{17} \mathrm{Al}_{12}$ & & $35-70$ \\
\hline & Al-Y-Fe(Mn) & $\begin{array}{l}\mathrm{Al}-(21-30) \mathrm{Y}-(0.4-8) \mathrm{Fe} \\
(0-0.2) \mathrm{Mn}\end{array}$ & $130-380$ \\
\hline & Al-Y & $\mathrm{Al}_{2} \mathrm{Y}$ & $60-90$ \\
\hline \multirow[t]{2}{*}{ Mg-9Al-0.5Ca } & $\beta-\mathrm{Mg}_{17} \mathrm{Al}_{12}(1.7$ at.\%Ca) & & $<25$ \\
\hline & $\mathrm{Al}-\mathrm{Fe}-\mathrm{Ca}(\mathrm{Mn})$ & $\begin{array}{l}\text { Al-(1-8)Fe-(0.7-1)Ca- } \\
(0-3.4) \mathrm{Mn}\end{array}$ & $<80$ \\
\hline \multirow[t]{2}{*}{ Mg-9Al-0.5Sn } & $\begin{array}{l}\beta-\mathrm{Mg}_{17} \mathrm{Al}_{12}(0.2 \text { at. } \% \\
\text { Sn) }\end{array}$ & & $90-100$ \\
\hline & Al-Mn-Fe-Sn & $\begin{array}{l}\mathrm{Al}-(18-22) \mathrm{Mn}-(3-8) \mathrm{Fe}- \\
0.2 \mathrm{Sn}\end{array}$ & $180-230$ \\
\hline
\end{tabular}

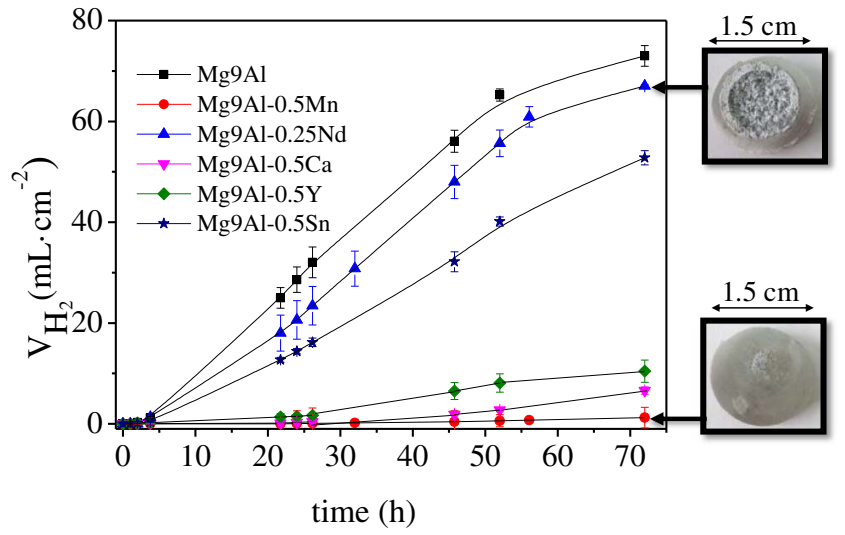

Fig. 7. Volume of hydrogen evolved from the cathodic reaction with immersion time of the studied magnesium alloys and surface appearance of $\mathrm{Mg}-9 \mathrm{Al}-0.25 \mathrm{Nd}$ and $\mathrm{Mg}-9 \mathrm{Al}-$ $0.5 \mathrm{Mn}$ alloys after the corrosion test.

Table 6

Corrosion rate calculated from $\mathrm{H}_{2}$ collection measurements and corrosion potential and cathodic current densities obtained from polarization curves.

\begin{tabular}{llll}
\hline Alloy & $P\left(\mathrm{mg} \mathrm{cm}^{-2} \mathrm{~d}^{-1}\right)$ & $E_{\text {corr }}\left(\mathrm{mV}_{\mathrm{Ag} / \mathrm{AgCl}}\right)$ & $i_{\text {corr }}\left(\mathrm{Acm}^{-2}\right)$ \\
\hline Mg-9Al & $27.1 \pm 0.7$ & -1.472 & $(8.6 \pm 0.6) \times 10^{-5}$ \\
Mg-9Al-0.5Mn & $0.4 \pm 0.1$ & -1.535 & $(5.2 \pm 0.7) \times 10^{-6}$ \\
Mg-9Al-0.25Nd & $24.2 \pm 0.1$ & -1.485 & $(4.34 \pm 0.01) \times 10^{-5}$ \\
Mg-9Al-0.5Ca & $2.4 \pm 0.2$ & -1.535 & $(5.5 \pm 0.6) \times 10^{-6}$ \\
Mg-9Al-0.5Y & $3.8 \pm 0.8$ & -1.525 & $(2.4 \pm 0.1) \times 10^{-5}$ \\
Mg-9Al-0.5Sn & $19.1 \pm 0.5$ & -1.511 & $(4.5 \pm 0.6) \times 10^{-5}$ \\
\hline
\end{tabular}

no evidence of $\mathrm{Nd}$ oxides in the composition of the passive layer on $\mathrm{Nd}$ modified AZ91 magnesium alloy [34]. Likewise, the anodic branches of the polarization curves show little influence of the minor additions on the passivity of the alloys (Fig. 8).

$\mathrm{Ca}$ and $\mathrm{Sn}$ additions to $\mathrm{Mg}-9 \mathrm{Al}$ alloy result in completely different microstructural modifications compared with $\mathrm{Mn}, \mathrm{Y}$ and $\mathrm{Nd}$. Both $\mathrm{Ca}$ and $\mathrm{Sn}$ are mainly associated with the $\beta$-phase and modify the electrochemical activity of the latter. The incorporation of Ca decreases the potential difference of the $\beta$-phase with the matrix, which results in less intense galvanic coupling. Additionally, $\mathrm{Ca}$ also reduces the potential difference of $\alpha$-Mg with Fe-rich intermetallics. As a result, a significant

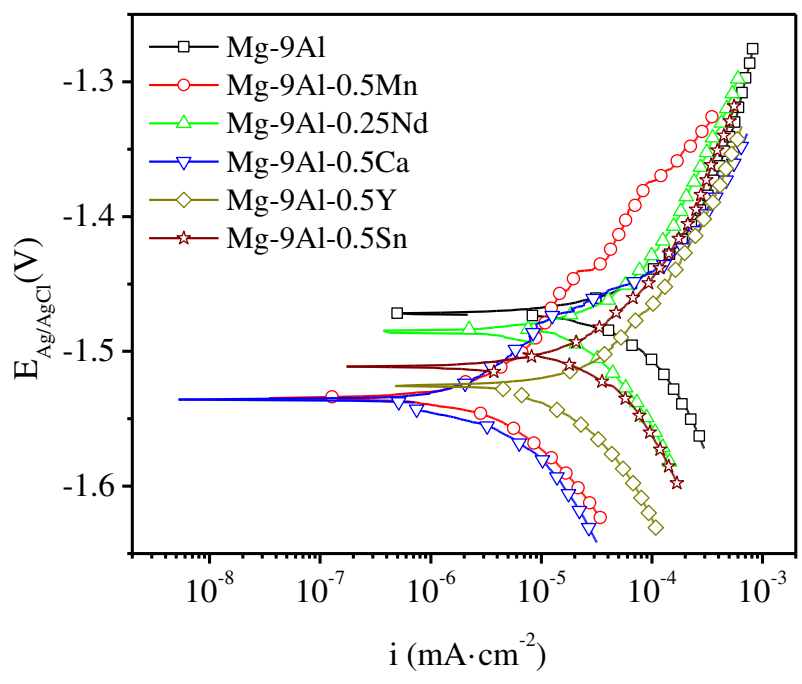

Fig. 8. Polarization curves of the investigated alloys after $1 \mathrm{~h}$ immersion in naturallyaerated $0.5 \mathrm{wt} \% \mathrm{NaCl}$ solution.

decrease of the corrosion rate is observed compared to the unmodified alloy (Fig. 7). This improvement is also associated with the microstructure refinement caused by $\mathrm{Ca}$ and with the higher area fraction of the $\beta$-phase. It has been reported repeatedly [10] that the barrier capacity of the $\beta$-phase against corrosion is intimately related to its morphology, distribution and relative amount and is strengthened in refined interconnected microstructures. The positive effect of $\mathrm{Ca}$ has been observed previously $[40,63]$, however its influence on the corrosion resistance depends greatly on the alloy composition and, therefore, on its microstructure. There are some published works where a negative effect of $\mathrm{Ca}$ on the corrosion resistance of $\mathrm{Mg}$ alloys was found, and it was associated with the formation of highly reactive $\mathrm{Mg}_{2} \mathrm{Ca}$ particles which can be responsible for galvanic coupling [64].

The corrosion rates of Mg-9Al magnesium alloy modified with $\mathrm{Sn}$ slightly decreases (Figs. 7 and 8). Sn tends to increase the potential difference of the $\beta$-phase due to its nobler nature compared with $\mathrm{Mg}$ and Al. It also tends to increase the $\beta$-phase area fraction, which, unlike $\mathrm{Ca}$, does not improve the corrosion resistance considerably. Usually, higher area fractions of $\beta$-phase result in better corrosion protection since the barrier effect prevails over the formation of galvanic couples between the $\beta$-phase and the matrix (those are usually not very intense) [11]. However, since Sn increases the potential difference between those microconstituents, the negative influence of the coupling overcomes the barrier effect of the $\beta$-phase, which explains the insignificant improvement in the corrosion resistance of Mg-9Al-0.5Sn compared with Mg-9Al. On the other hand, the addition of Sn did not increase the potential value of intermetallics, probably due to the low $\mathrm{Sn} / \mathrm{Fe}$ ratio in those compounds.

Nam [65] analysed the influence of Sn concertation (1-4 wt $\%$ ) on the corrosion behaviour of an extruded Mg-5Al alloy and observed a clear positive influence of Sn. However, there were significant microstructural differences compared with the alloys studied in the present work: (i) Sn was identified both in $\alpha$-solid solution and in the form of $\mathrm{Mg}_{2} \mathrm{Sn}$ and (ii) the amount of $\beta$-phase was very low. The authors attributed the improvement in the corrosion resistance to the incorporation of $\mathrm{Sn}$ into the corrosion products layer which provided extra protection to the alloy. Comparison with the literature suggests that Sn probably exhibits a competitive behaviour: it promotes galvanic coupling if incorporated into the $\beta$-phase in the form of $\mathrm{Sn}_{2} \mathrm{Mg}$, and is beneficial if exists in a solid solution. The slightly better corrosion resistance of Sn-modified alloy can also be related to the lower area fraction of Fe-rich intermetallics as determined by image analysis (Table 4).

From the earliest classical works of Boyer [66] and Hanawalt [13], 

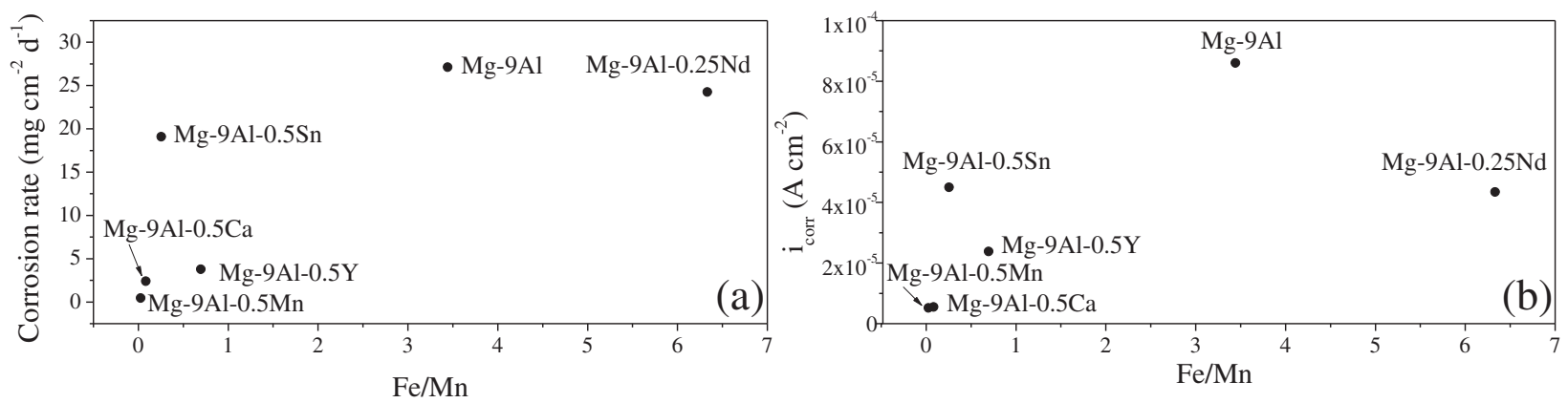

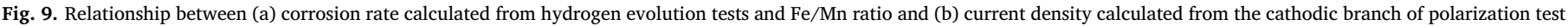
and $\mathrm{Fe} / \mathrm{Mn}$ ratio.

it has been known that the corrosion rate of $\mathrm{Mg}$ is greatly influenced by the presence of impurities. It has also been empirically determined that when $\mathrm{Mn}$ is added to $\mathrm{Mg}$ - $\mathrm{Al}$ alloys, yielding a $\mathrm{Fe} / \mathrm{Mn}$ ratio below $0.020-0.032$, the detrimental effect of Fe impurity is greatly reduced. On the contrary, when the $\mathrm{Fe} / \mathrm{Mn}$ ratio is above 0.032 , the corrosion rate of $\mathrm{Mg}$-Al alloys rapidly increases, typically in a linear fashion [13].

Fig. 9 shows the relationship between the Fe/Mn ratio and the corrosion rate values of studied alloys. Ideally, in order to elucidate the effect of each element, it would be necessary to compare alloys with the same Fe/Mn ratio. That is not the case in the present study. Still, some conclusions can be drawn from these results. The corrosion rate increases with the Fe/Mn ratio, but not linearly. This evidences that the alloying elements play a decisive role in the corrosion response (note that with the exception of the Mn-modified alloy, all the investigated alloys exceed the Fe/Mn tolerance limit of 0.032).

In case of Mg-9Al-0.5Y and Mg-9Al-0.5Ca, there is no notable increase neither in the corrosion rate nor in the $i_{\text {corr }}$ compared with the $\mathrm{Mg}-9 \mathrm{Al}-0.5 \mathrm{Mn}$, proving the positive effect of these two elements (Ca and $\mathrm{Y}$ ). Corrosion rates of $\mathrm{Y}$ - and Ca-modified alloys are below $5 \mathrm{mg} \mathrm{cm}^{-2} \mathrm{~d}^{-1}$ which is usually not observed for $\mathrm{Mg}$-Al alloys with $\mathrm{Fe}$ above its tolerance limit [13].

Both hydrogen collection and electrochemical measurements reveal the poor corrosion performance of the Sn-modified alloy. The present study suggests that this behaviour is related to Sn promoting a more active coupling phenomenon between the $\beta$-phase and the $\alpha$-Mg matrix. However, in order to confirm this, it would be necessary to determine the corrosion rate of a $\mathrm{Sn}$-free $\mathrm{Mg}$-9Al with a similar $\mathrm{Fe} / \mathrm{Mn}$ ratio.

Finally, the Mg-9Al-0.25Nd alloy, despite having the highest Fe/Mn ratio of all alloys, shows lower corrosion rates than the Mg-9Al alloy used as a reference, which proves the positive effect of Nd. Future studies with this alloying element and different $\mathrm{Fe} / \mathrm{Mn}$ ratios would help to elucidate the true potential of this element as Fe scavenger.

These results suggest that $\mathrm{Ca}, \mathrm{Y}$ and $\mathrm{Nd}$ have a great potential for improving the corrosion performance of commercial Mg-9Al alloys, especially if they are used in combination for refinement of the microstructure (Ca, $\mathrm{Nd}$ ), suppression of microgalvanic corrosion between the $\beta$ and $\alpha$ phases (Ca) and reduction of the detrimental effect of $\mathrm{Fe}$ impurities (Ca, Y and $\mathrm{Nd}$ ).

\section{Conclusions}

The following conclusions can be drawn from the present study:

- From a microstructural point of view, all the studied materials present $\alpha$-Mg dendrites and a partial divorced eutectic $\alpha-\mathrm{Mg}_{\text {eut }} / \beta$ $\mathrm{Mg}_{17} \mathrm{Al}_{12}$ located at the interdendritic spaces. The unmodified alloy (Mg-9Al) also presents Fe-rich intermetallic particles, mainly Al-Fe (Mn). The addition of minor quantities of $\mathrm{Mn}, \mathrm{Nd}$ and $\mathrm{Y}$ increases the grain size and does not affect the nature of the $\beta$-phase (composition and area fraction). The additions tend to be incorporated into Al-rich particles. On the contrary, $\mathrm{Ca}$ and $\mathrm{Sn}$ act as grain refiners and tend to be incorporated into the eutectic aggregate, increasing considerably the area fraction of the latter.

- SKPFM studies of the unmodified alloy revealed a potential difference between $\alpha-\mathrm{Mg}$ and $\beta$-phase of $35-70 \mathrm{mV}$. The addition of $\mathrm{Mn}$, $\mathrm{Nd}$ and $\mathrm{Y}$ does not alter this value. On the contrary, the incorporation of Ca decreases it to values below $25 \mathrm{mV}$ and $\mathrm{Sn}$ increases it to $90-100 \mathrm{mV}$. Regarding the intermetallic particles, all the studied alloying elements tend to decrease the potential difference of $\mathrm{Al}$-rich inclusions, reaching minimum values in case of $\mathrm{Mg}$ 9Al-0.5Ca $(80 \mathrm{mV})$.

- Hydrogen collection and potentiodynamic corrosion tests show that the addition of $\mathrm{Mn}, \mathrm{Y}$ and Ca reduces the corrosion rate by $>80 \%$ compared to the unmodified alloy. In case of Mn and Y such improvement is attributed to their incorporation into the Al-rich intermetallics which reduces the intensity of coupling phenomenon. A similar response was expected for Nd-modified alloy, however, scarce enhancement was observed, probably due to the low amount of $\mathrm{Nd}$ present in the alloy. The positive effect of $\mathrm{Ca}$ on the corrosion resistance is related to the refinement of the microstructure, to the reduction of the intensity of galvanic couples formed between the $\beta$ phase and the $\alpha-\mathrm{Mg}$ matrix and to the increase of the $\beta$-phase area fraction which improves the barrier effect of the latter. Sn slightly increases the corrosion resistance which is related to the lower area fraction of Al-rich intermetallics.

\section{Acknowledgments}

The authors are grateful to MINECO (Spain, project MAT201566334-C03-03-R) for financial support. M. Mohedano is grateful to the MICINN (Spain) for financial support via Juan de la Cierva Programme (IJCI-2014-19117) and Young Researchers Challenges Programme (Proyectos Retos Jovenes Investigadores) (MAT2015-73355-JIN).

\section{References}

[1] H. Friedrieh, B. Mordike, Magnesium Technology: Metallurgy, Design Data, Application, Springer-Verlag, Berlin Heidelberg, Berlin, Germany, 2006.

[2] H. Westengen, H.M.M.A. Rashed, Magnesium: Alloying, Reference Module in Materials Science and Materials Engineering, Elsevier, 2016.

[3] A.A. Luo, 8 - Applications: aerospace, automotive and other structural applications of magnesium, Fundamentals of Magnesium Alloy Metallurgy, Woodhead Publishing, 2013, pp. 266-316.

[4] G.-L. Song, Corrosion of Magnesium Alloys, Elsevier, 2011.

[5] F. Pan, X. Chen, T. Yan, T. Liu, J. Mao, W. Luo, Q. Wang, J. Peng, A. Tang, B. Jiang, A novel approach to melt purification of magnesium alloys, J. Magnesium Alloys 4 (1) (2016) 8-14.

[6] M.K. Kulekci, Magnesium and its alloys applications in automotive industry, Int. J. Adv. Manuf. Technol. 39 (9-10) (2008) 851-865.

[7] G.L. Song, A. Atrens, Corrosion mechanisms of magnesium alloys, Adv. Eng. Mater. 1 (1) (1999) 11-33.

[8] G. Song, A.L. Bowles, D.H. StJohn, Corrosion resistance of aged die cast magnesium alloy AZ91D, Mater. Sci. Eng. A 366 (1) (2004) 74-86.

[9] R. Arrabal, E. Matykina, A. Pardo, M.C. Merino, K. Paucar, M. Mohedano, P. Casajús, Corrosion behaviour of AZ91D and AM50 magnesium alloys with $\mathrm{Nd}$ and Gd additions in humid environments, Corros. Sci. 55 (0) (2012) 351-362. 
[10] B. Mingo, R. Arrabal, M. Mohedano, A. Pardo, E. Matykina, A. Rivas, Enhanced corrosion resistance of AZ91 alloy produced by semisolid metal processing, J. Electrochem. Soc. 162 (4) (2015) C180-C188.

[11] A. Pardo, M.C. Merino, A.E. Coy, F. Viejo, R. Arrabal, S. Feliú Jr., Influence of microstructure and composition on the corrosion behaviour of $\mathrm{Mg} / \mathrm{Al}$ alloys in chloride media, Electrochim. Acta 53 (27) (2008) 7890-7902.

[12] G. Song, A. Atrens, M. Dargusch, Influence of microstructure on the corrosion of diecast AZ91D, Corros. Sci. 41 (2) (1998) 249-273.

[13] J.D. Hanawalt, C.E. Nelson, J.A. Peloubet, Corrosion studies of magnesium and its alloys, Trans. Metall. Soc. AIME 147 (1942).

[14] L. Yang, X. Zhou, S.-M. Liang, R. Schmid-Fetzer, Z. Fan, G. Scamans, J. Robson, G. Thompson, Effect of traces of silicon on the formation of Fe-rich particles in pure magnesium and the corrosion susceptibility of magnesium, J. Alloys Compd. 619 (2015) 396-400.

[15] A. Prasad, P.J. Uggowitzer, Z. Shi, A. Atrens, Production of high purity magnesium alloys by melt purification with Zr, Adv. Eng. Mater. 14 (7) (2012) 477-490.

[16] M. Liu, P.J. Uggowitzer, A.V. Nagasekhar, P. Schmutz, M. Easton, G.-L. Song, A. Atrens, Calculated phase diagrams and the corrosion of die-cast $\mathrm{Mg}-\mathrm{Al}$ alloys, Corros. Sci. 51 (3) (2009) 602-619.

[17] H. Friedrich, B. Mordike, Magnesium Technology: Metallurgy Design Data, Automotive Applications, Springer Verlag, Dusseldorf, Germany, 2005 (2006).

[18] D. Gandel, M. Easton, M. Gibson, N. Birbilis, Influence of Mn and Zr on the corrosion of $\mathrm{Al}$-free $\mathrm{Mg}$ alloys: part 1-electrochemical behavior of $\mathrm{Mn}$ and $\mathrm{Zr}$, Corrosion 69 (7) (2012) 666-671.

[19] H. Robinson, P. George, Effect of alloying and impurity elements in magnesium alloy cast anodes, Corrosion 10 (6) (1954) 182-188.

[20] K. Gusieva, C. Davies, J. Scully, N. Birbilis, Corrosion of magnesium alloys: the role of alloying, Int. Mater. Rev. 60 (3) (2015) 169-194.

[21] H. Matsubara, Y. Ichige, K. Fujita, H. Nishiyama, K. Hodouchi, Effect of impurity Fe on corrosion behavior of AM50 and AM60 magnesium alloys, Corros. Sci. 66 (2013) 203-210.

[22] D. Gandel, N. Birbilis, M. Easton, M. Gibson, The Influence of Mn on the Corrosion of Al-Free Mg Alloys, 18th Int. Corros. Cong, 2011 International Corrosion Congress, Perth, Australia, 2011, pp. 1-9.

[23] D. Gandel, N. Birbilis, M. Easton, M. Gibson, Influence of manganese, zirconium and iron on the corrosion of magnesium, Proceedings of Corrosion \& Prevention, 2010, pp. 875-885.

[24] K. Reichek, K. Clark, J. Hillis, Controlling the Salt Water Corrosion Performance of Magnesium AZ91 Alloy, SAE Technical Paper, 1985.

[25] O. Lunder, T.K. Aune, K. Nisancioglu, Effect of Mn additions on the corrosion behavior of mould-cast magnesium ASTM AZ91, Corrosion 43 (5) (1987) 291-295.

[26] J.E. Hillis, K. Reichek, High Purity Magnesium AM60 Alloy: The Critical Contaminant Limits and the Salt Water Corrosion Performance (SAE Technical Paper), (1986).

[27] W.E. Mercer, J.E. Hillis, The Critical Contaminant Limits and Salt Water Corrosion Performance of Magnesium AE42 Alloy (SAE Technical Paper), (1992).

[28] J.E. Hillis, S.O. Shook, Composition and Performance of an Improved Magnesium AS41 Alloy (SAE Technical Paper), (1989).

[29] G.H. Wu, H.T. Gao, W.J. Ding, Y.P. Zhu, Study on mechanism of iron reduction in magnesium alloy melt, J. Mater. Sci. 40 (23) (2005) 6175-6180.

[30] F. Cao, Z. Shi, G.-L. Song, M. Liu, A. Atrens, Corrosion behaviour in salt spray and in $3.5 \% \mathrm{NaCl}$ solution saturated with $\mathrm{Mg}(\mathrm{OH}) 2$ of as-cast and solution heat-treated binary Mg-X alloys: X = Mn, Sn, Ca, Zn, Al, Zr, Si, Sr, Corros. Sci. 76 (2013) 60-97.

[31] Z. Li, M. Chen, W. Li, H. Zheng, C. You, D. Liu, F. Jin, The synergistic effect of trace $\mathrm{Sr}$ and $\mathrm{Zr}$ on the microstructure and properties of a biodegradable Mg-Zn-Zr-Sr alloy, J. Alloys Compd. 702 (2017) 290-302.

[32] B. Langelier, G. Sha, A. Korinek, P. Donnadieu, S.P. Ringer, S. Esmaeili, The effects of microalloying on the precipitate microstructure at grain boundary regions in an Mg-Zn-based alloy, Mater. Des. 119 (2017) 290-296.

[33] Y. Jiang, Y.a. Chen, J. Gao, Comparative study regarding the effect of Al, Zn, and Gd on the microstructure and mechanical properties of $\mathrm{Mg}$ alloy Mg-Sn-Li, Mater. Des. 105 (2016) 34-40.

[34] R. Arrabal, B. Mingo, A. Pardo, E. Matykina, M. Mohedano, M.C. Merino, A. Rivas, A. Maroto, Role of alloyed Nd in the microstructure and atmospheric corrosion of as-cast magnesium alloy AZ91, Corros. Sci. 97 (2015) 38-48.

[35] R. Jia, M. Zhang, L. Zhang, W. Zhang, F. Guo, Correlative change of corrosion behavior with the microstructure of AZ91 Mg alloy modified with Y additions, J. Alloys Compd. 634 (2015) 263-271.

[36] W. Liu, F. Cao, L. Zhong, L. Zheng, B. Jia, Z. Zhang, J. Zhang, Influence of rare earth element Ce and La addition on corrosion behavior of AZ91 magnesium alloy, Mater. Corros. 60 (10) (2009) 795-803.

[37] S. Tekumalla, M. Gupta, An insight into ignition factors and mechanisms of magnesium based materials: a review, Mater. Des. 113 (2017) 84-98.

[38] W. Feng, W. Yue, P.-L. Mao, B.-Y. Yu, Q.-Y. Guo, Effects of combined addition of Y and $\mathrm{Ca}$ on microstructure and mechanical properties of die casting AZ91 alloy, Trans. Nonferrous Metals Soc. China 20 (2010) s311-s317.
[39] A. Südholz, N. Kirkland, R. Buchheit, N. Birbilis, Electrochemical properties of intermetallic phases and common impurity elements in magnesium alloys, Electrochem. Solid-State Lett. 14 (2) (2011) C5-C7.

[40] J. Yang, J. Peng, E.A. Nyberg, F.-s. Pan, Effect of Ca addition on the corrosion behavior of Mg-Al-Mn alloy, Appl. Surf. Sci. 369 (2016) 92-100.

[41] K.H. Kim, N.D. Nam, J.G. Kim, K.S. Shin, H.C. Jung, Effect of calcium addition on the corrosion behavior of $\mathrm{Mg}-5 \mathrm{Al}$ alloy, Intermetallics 19 (12) (2011) 1831-1838.

[42] M. Mezbahul-Islam, A.O. Mostafa, M. Medraj, Essential magnesium alloys binary phase diagrams and their thermochemical data, J. Mater. 2014 (2014) 33.

[43] M. Srinivas, S.K. Adapaka, L. Neelakantan, Solubility effects of Sn and Ga on the microstructure and corrosion behavior of Al-Mg-Sn-Ga alloy anodes, J. Alloys Compd. 683 (2016) 647-653.

[44] D. StJohn, M. Easton, M. Qian, J. Taylor, Grain refinement of magnesium alloys: a review of recent research, theoretical developments, and their application, Metall. Mater. Trans. A 44 (7) (2013) 2935-2949.

[45] Z. Shi, M. Liu, A. Atrens, Measurement of the corrosion rate of magnesium alloys using Tafel extrapolation, Corros. Sci. 52 (2) (2010) 579-588.

[46] B. Mingo, R. Arrabal, M. Mohedano, A. Pardo, E. Matykina, Corrosion and wear of PEO coated AZ91/SiC composites, Surf. Coat. Technol. 309 (2017) 10.

[47] J. She, F.S. Pan, H.H. Hu, A.T. Tang, Z.W. Yu, K. Song, Effect of $\mathrm{Mg}_{2} \mathrm{Sn}$ intermetallic on the grain refinement in As-cast AM series alloy, J. Mater. Eng. Perform. 24 (8) (2015) 2937-2943.

[48] Y.C. Lee, A.K. Dahle, D.H. StJohn, The role of solute in grain refinement of magnesium, Metall. Mater. Trans. A 31 (11) (2000) 2895-2906.

[49] G. Wu, Y. Fan, H. Gao, C. Zhai, Y.P. Zhu, The effect of Ca and rare earth elements on the microstructure, mechanical properties and corrosion behavior of AZ91D, Mater. Sci. Eng. A 408 (1-2) (2005) 255-263.

[50] B. Kondori, R. Mahmudi, Effect of Ca additions on the microstructure, thermal stability and mechanical properties of a cast AM60 magnesium alloy, Mater. Sci. Eng. A 527 (7-8) (2010) 2014-2021.

[51] A. Suzuki, N.D. Saddock, J.W. Jones, T.M. Pollock, Solidification paths and eutectic intermetallic phases in Mg-Al-Ca ternary alloys, Acta Mater. 53 (9) (2005) 2823-2834.

[52] A. Suzuki, N.D. Saddock, J.W. Jones, T.M. Pollock, Structure and transition of eutectic $(\mathrm{Mg}, \mathrm{Al}) 2 \mathrm{Ca}$ Laves phase in a die-cast Mg-Al-Ca base alloy, Scr. Mater. 51 (10) (2004) 1005-1010.

[53] J. Yang, D. Yi, S. Deng, B. Wang, G. Liu, Effect of trace Ce on the microstructure and corrosion resistance of AZ91 magnesium alloy, J. Chin. Soc. Corrosion Protection 4 (2008) 004.

[54] J. Yang, D.-q. Yi, S.-h. Deng, Effect of trace Nd on microstructure and corrosion resistance of AZ91 magnesium alloy, Adv. Mater. Sci. Eng. (Hangzhou) 26 (2) (2008) 251.

[55] A. Janz, J. Gröbner, H. Cao, J. Zhu, Y.A. Chang, R. Schmid-Fetzer, Thermodynamic modeling of the Mg-Al-Ca system, Acta Mater. 57 (3) (2009) 682-694.

[56] A. Boby, A. Srinivasan, U.T.S. Pillai, B.C. Pai, Mechanical characterization and corrosion behavior of newly designed Sn and Y added AZ91 alloy, Mater. Des. 88 (2015) 871-879.

[57] E. Doernberg, A. Kozlov, R. Schmid-Fetzer, Experimental investigation and thermodynamic calculation of $\mathrm{Mg}$-Al-Sn phase equilibria and solidification microstructures, J. Phase Equilib. Diffus. 28 (6) (2007) 523-535.

[58] J. She, F. Pan, P. Peng, A. Tang, Z. Yu, L. Wu, H. Pan, C. Zhao, Z. Gao, S. Luo, Microstructure and mechanical properties of asextruded Mg-x Al-5Sn-0.3Mn alloys ( $x=1,3,6$ and 9), Mater. Sci. Technol. 31 (3) (2015) 344-348.

[59] F. Andreatta, I. Apachitei, A. Kodentsov, J. Dzwonczyk, J. Duszczyk, Volta potential of second phase particles in extruded AZ80 magnesium alloy, Electrochim. Acta 51 (17) (2006) 3551-3557.

[60] M. Jönsson, D. Thierry, N. LeBozec, The influence of microstructure on the corrosion behaviour of AZ91D studied by scanning Kelvin probe force microscopy and scanning Kelvin probe, Corros. Sci. 48 (5) (2006) 1193-1208.

[61] G. Ben-Hamu, D. Eliezer, C.E. Cross, T. Böllinghaus, The relation between microstructure and corrosion behavior of GTA welded AZ31B magnesium sheet, Mater. Sci. Eng. A 452-453 (2007) 210-218.

[62] W. He, E. Zhang, K. Yang, Effect of Y on the bio-corrosion behavior of extruded Mg-Zn-Mn alloy in Hank's solution, Mater. Sci. Eng. C 30 (1) (2010) 167-174.

[63] H.R. Bakhsheshi-Rad, M.H. Idris, M.R. Abdul-Kadir, A. Ourdjini, M. Medraj, M. Daroonparvar, E. Hamzah, Mechanical and bio-corrosion properties of quaternary $\mathrm{Mg}-\mathrm{Ca}-\mathrm{Mn}-\mathrm{Zn}$ alloys compared with binary Mg-Ca alloys, Mater. Des. 53 (2014) 283-292.

[64] N.T. Kirkland, N. Birbilis, J. Walker, T. Woodfield, G.J. Dias, M.P. Staiger, In vitro dissolution of magnesium-calcium binary alloys: clarifying the unique role of calcium additions in bioresorbable magnesium implant alloys, J. Biomed. Mater. Res. B Appl. Biomater. 95 (1) (2010) 91-100.

[65] N. Nam, V. Thu, N. To, Effect of tin on the corrosion of Mg-5Al based alloy in $3.5 \mathrm{wt}$. \% NaCl Solution, Int. J. Metall. Mater. Eng. 1 (2015) 118.

[66] J. Boyer, The Corrosion of Magnesium and of the Magnesium Aluminum Alloys Containing Manganese, (1927). 